\title{
Relevance and Effectiveness of the WHO Global Code Practice on the International Recruitment of Health Personnel - Ethical and Systems Perspectives
}

\author{
Ruairí Brugha* and Sophie Crowe
}

\begin{abstract}
The relevance and effectiveness of the World Health Organization's (WHO's) Global Code of Practice on the International Recruitment of Health Personnel is being reviewed in 2015. The Code, which is a set of ethical norms and principles adopted by the World Health Assembly (WHA) in 2010, urges members states to train and retain the health personnel they need, thereby limiting demand for international migration, especially from the under-staffed health systems in lowand middle-income countries. Most countries failed to submit a first report in 2012 on implementation of the Code, including those source countries whose health systems are most under threat from the recruitment of their doctors and nurses, often to work in 4 major destination countries: the United States, United Kingdom, Canada and Australia. Political commitment by source country Ministers of Health needs to have been achieved at the May 2015 WHA to ensure better reporting by these countries on Code implementation for it to be effective. This paper uses ethics and health systems perspectives to analyse some of the drivers of international recruitment. The balance of competing ethics principles, which are contained in the Code's articles, reflects a tension that was evident during the drafting of the Code between 2007 and 2010. In 2007-2008, the right of health personnel to migrate was seen as a preeminent principle by US representatives on the Global Council which co-drafted the Code. Consensus on how to balance competing ethical principles - giving due recognition on the one hand to the obligations of health workers to the countries that trained them and the need for distributive justice given the global inequities of health workforce distribution in relation to need, and the right to migrate on the other hand - was only possible after President Obama took office in January 2009. It is in the interests of all countries to implement the Global Code and not just those that are losing their health personnel through international recruitment, given that it calls on all member states "to educate, retain and sustain a health workforce that is appropriate for their (need) ...” (Article 5.4), to ensure health systems' sustainability. However, in some wealthy destination countries, this means tackling national inequities and poorly designed health workforce strategies that result in foreign-trained doctors being recruited to work among disadvantaged populations and in primary care settings, allowing domestically trained doctors work in more attractive hospital settings.

Keywords: Global Code, International Recruitment, Health Personnel, Distributive Justice

Copyright: @ 2015 by Kerman University of Medical Sciences

Citation: Brugha R, Crowe S. Relevance and effectiveness of the WHO Global Code Practice on the International Recruitment of Health Personnel - ethical and systems perspectives. Int J Health Policy Manag. 2015;4(6):333-336. doi: $10.15171 /$ ijhpm.2015.103
\end{abstract}

Article History:

Received: 17 April 2015 Accepted: 19 May 2015 ePublished: 20 May 2015

*Correspondence to: Ruairí Brugha Email: rbrugha@rcsi.ie

\section{What Is the WHO Global Code?}

In May 2015, a report is being made to the World Health Assembly (WHA) by an expert advisory group, established by the World Health Organization (WHO), on the relevance and effectiveness of the Global Code of Practice on the International Recruitment of Health Personnel (the Code). ${ }^{1,2}$ Adopted by the WHA in May 2010, the Code is a 'groundbreaking legal instrument, ${ }^{2}$ which provides ethical norms and principles for governing intercountry relations. A 2004 resolution of the WHA had requested the WHO to develop a voluntary code of practice on international recruitment, which was achieved through a 3 -year process, including 8 international meetings from 2007 to 2010 , where the drafting was undertaken by the WHO, a Global Policy Advisory Council and a Technical Working Group. ${ }^{3}$ The outcome was a voluntary instrument that, while not legally binding on member states, is an "expression of the solemn will... of the international community." ${ }^{2}$ Its primary purpose is to protect vulnerable source countries whose health systems are undermined through losing scarce health professionals to wealthy destination countries. ${ }^{3,4}$

Recent articles have questioned the relevance and effectiveness of the Code, ${ }^{5,6}$ given lack of awareness or perhaps lack of concern about the requirements of the Code in some destination countries; and a lack of reporting by most source countries. ${ }^{4,5}$ It has been suggested that the voluntary nature of the Code means that it has limited impact on destination country recruitment practices. ${ }^{6}$ However, the 'pull' of demand, more than its voluntary nature, appears to account for an acceleration in migration by health professionals to the United States in the post-Code era. Tankwanchi et $\mathrm{al}^{7}$ propose that a combination of "professional incentives and favorable immigration policies" is "luring" Sub-Saharan African (SSA) doctors and nurses to emigrate to the United States. As a 
voluntary code, the few teeth that it has are found in Article 9.1, which states that: "Members states should periodically report the measures taken" to implement the Code. ${ }^{1}$

Scepticism about its effectiveness and potential may be premature. However, if low levels of reporting in $2012^{4}-$ attributed to lack of technical and financial resources, lack of awareness and poor political commitment in source countries ${ }^{2}$ - are replicated in Round Two, set to take place between March and July 2015, the Code's sceptics will be justified. In which case the ineffectiveness of the Code will be due in large measure to a failure of the source countries with the greatest need to take the necessary steps to ensure its implementation. Hence, the 68th WHA, attended by Ministers of Health from many source country member states, has particular importance for protecting the sustainability of their health workforces.

\section{Health Workforce Migration}

Migration of labour in search of opportunity and livelihood, which is a guiding principle (3.4) and right that is recognised in the Code, ${ }^{1}$ is as old as the human race. Its consequences for the health systems of source countries became evident in a series of studies on the emigration of doctors from the United Kingdom, mainly to North America, published during the 1960s and 1970s. ${ }^{8}{ }^{89}$ The global scale and consequences of migration, in terms of the maldistribution of health workers, was synthesised in the 2006 World Health Report. ${ }^{10}$ This report's statistics are still quoted ${ }^{11,12}: 36$ of the 57 countries with critical shortages are in Africa, which has $25 \%$ of the world's burden of disease, but only $3 \%$ of health workers worldwide and $1 \%$ of global economic resources. ${ }^{10,11}$ Whereas, the United States - with $4 \%$ of the world's population - has $8 \%$ of the doctors and $17 \%$ of the nurses. ${ }^{12}$ Such statistics embody the Biblical statement (Matthew 13:12): "For whoever has, to him more shall be given, and he will have an abundance; but whoever does not have, even what he has shall be taken away from him" - except in one respect. Rather than there being an abundance, there are growing shortages of health professionals worldwide, exacerbated by ageing populations, increasing expectations and demand. WHO 2006 estimates of a global shortage of 4.3 million doctors and nurses are still quoted. ${ }^{10,12}$

Underlying the global figures are some of the drivers for migration, especially the 'pull' factors that continue to suck the life-blood - frontline doctors and nurses - from source country health systems, often from the poorest to the wealthiest countries. In the United States, a shortage of 85000 doctors is projected for $2020^{12}$; and recent research suggests that by May 2015, 22.7\% of SSA medical graduates in the United States will have been recruited since implementation of the Code, representing an acceleration in the migration of SSA medical graduates to the United States in the years since the Code was adopted. ${ }^{13}$ If member states, especially the wealthier destination countries, were to train and retain the health workers they need to meet domestic demand, in line with Article 5.4 of the Code, then such large scale migratory flows from poor to wealthy countries should reduce. However, Code reporting and monitoring will serve little if limited to naming and occasionally shaming. There is a need instead for analyses of the drivers of international recruitment within the major destination countries; and to stimulate debate about how implementation of the Code can serve the interests of destination (recruiting) as well as source countries.

\section{Analytical Lenses}

Recent analyses of the make-up and distribution of the medical and nursing workforce within the United States demonstrate how inherent imbalances and inequities within the United States health systems help to explain the refractory nature of some of these 'pull' factors. Chen et al ${ }^{14}$ in their 2013 study of the United States healthcare workforce, reported not only the high proportion (26\%) of foreign-trained doctors, but also how foreign doctors were more likely than their UStrained counterparts to work in unpopular settings (poorer inner cities); in less popular specialties (primary care); and disproportionately serve poor and vulnerable patients. This phenomenon, where foreign-trained doctors practice in areas where there are shortages of domestically trained doctors, was reported 30 years ago ${ }^{15}$; and is not unique to the United States. Canada has long relied on foreign-trained health professionals to address shortages in rural and remote locations ${ }^{16}$; as has Australia, where foreign-trained doctors often become general practitioners in rural and remote areas, which can be a condition for obtaining a visa. ${ }^{17}$ In a series of published and forthcoming studies, part of a body of evidence informing the deliberations of the WHO Expert Advisory Group which is reviewing the Relevance and Effectiveness of the Code in 2015, we report a similar phenomenon in Ireland. ${ }^{18}$

We propose 2 inter-connected lenses-an ethics and a health systems lens-through which to analyse health worker migration, both of which were central to the debates among those drafting the Code, ${ }^{[1]}$ and are reflected in its guiding principles (Article 3) and across its 10 articles. ${ }^{1}$ The guiding principles outline the duties of developed (destination) countries to strengthen health systems, especially in developing (source) countries (Article 3.3). They call for adherence to ethical principles in the international recruitment of health personnel (Article 3.5); highlight the duty of all countries to work towards health workforce sustainability (3.6); and call for a balance between the right to the highest attainable standard of health of source country populations and the rights of health personnel to migrate (3.4). ${ }^{1}$ Managing the inherent tension between these competing ethical principles requires leadership and effective health workforce management in both source and destination countries, but also a commitment by the latter to recognise the ethical imperatives of distributive justice (see below) that should not be sacrificed on the altar of expediency.

An ethical perspective or lens, pointing to the need for an ethical response to the global inequities in health personnel distribution, was central to the WHO 2006 World Report ${ }^{8,10}$; and is found in sociological analyses that suggest that recruitment and migration demonstrate that "the uneven global development of capital is at work." ${ }^{19}$ Aluttis et al, ${ }^{6}$ discussing the consequences of market approaches, reported that there was an increase from approximately 40 to 270 companies engaged in international nurse recruitment in the United States between the late 1990s and mid-2000s. This and Zubaran's paper ${ }^{9}$ contrast the ethical principle of autonomy - reflected in Article 3.4 of the Code: "Nothing in 
this Code should be interpreted as limiting the freedom of personnel... to migrate" 1 - with the principle of distributive justice (promoting equity) and social accountability. The case for distributive justice and global accountability around international recruitment was strengthened by Mills et al's 2011 paper, which estimated the costs to 9 SSA countries from the loss of locally trained medical doctors who were working in the four main destination countries: United States, United Kingdom, Canada and Australia. ${ }^{20}$ Estimates of losses ranged from $\$ 2.16$ million for Malawi to $\$ 1.41$ billion for South Africa, resulting in cost savings to destination countries that did not need to train the doctors they recruited internationally: \$2.7 billion for the United Kingdom and \$846 million for the United States. ${ }^{20}$

A health systems' and health workforce analysis lens is no less important; and in some ways, the title of the WHO Global Code of Practice on the International Recruitment of Health Personnel is a misnomer, in that it does not capture the underlying drivers of migration, which derive from source countries' inability to retain and employ the health professionals they train; and in some destination countries an unwillingness or failure to train sufficient numbers. The cornerstone and overarching principle of the Code is not to be found in Article 4, 'Responsibilities, rights and recruitment practices', but in Article 5. At its heart, the case for Code implementation comes from self-interest: "Member states should take effective measures to educate, retain and sustain a health workforce that is appropriate for the specific conditions of each country, including areas of greatest need... (and) meet their health personnel needs within their own human resources for health, as far as possible" (Article 5.4). ${ }^{1}$ Therein lies a unifying principle that brings together the health workforce rationale and the health equity/ethics case for why destination as well as source countries should implement the Code. Destination countries' needs can best be met by training their own health professionals, for whom cultural awareness and communication skills are to a great extent already a 'given', with the additional benefit of not depriving other countries of the health professionals they have trained.

\section{Ethics and Politics}

Political tensions between the position adopted by one destination country (the United States) and the other members of the Global Policy Advisory Council emerged at several points during the 2007-2010 Global Code development process. ${ }^{3}$ In 2009, there was a sea-change in the attitude of the US representatives on the Global Advisory Council, from the latter days of the President George W. Bush administration to the period after President Obama's inauguration. The Washington June 2009 meeting addressed by Senator Tom Daschle, after President Obama took up office, was a celebratory affair. It contrasted with the funereal atmosphere of a similar meeting in Geneva a year earlier, when the possibility of consensus on any form of Global Code appeared to be a receding dream, given the position of the United States delegates on the Council. These tensions reemerged a year later during the negotiation of the Code at the 63rd WHA, May 2010, when articles that enshrined the principle of 'ethical recruitment practices', which had been crafted over three years of international meetings, were challenged in the final three days of negotiations. Consensus was maintained, however, and the Code that was endorsed had retained its ethical force. These events, which were partly captured by Taylor and Dhillon, ${ }^{3}$ demonstrate how the national strategic interests of powerful member states can 'trump' the ethical positions that such states also seek to champion.

\section{Relevance and Effectiveness of the WHO Global Code}

If the WHO Global Code of Practice on the International Recruitment of Health Personnel is to have sustainable relevance and become effective, it needs to be supported by evidence. While Article 5 (Health workforce development and health systems sustainability) may be the cornerstone of the Code, and Article 4 (Responsibilities, rights and recruitment practices) frames the ethical debates, the oxygen keeping the Code alive will be derived from those articles that underpin and need to be used to demonstrate the Code's effectiveness: Article 6-Data gathering and research, Article 7-Information exchange; and Article 9-Monitoring and institutional relationships. Better routine data systems and monitoring are needed to produce statistics and to track trends in health worker migration. This requires destination countries to record and report on the inward migration of health workers, especially those from the poorest and most fragile health systems of SSA, given the difficulties in tracking outward migration from these countries, which contributes in turn to nonreporting by source countries.

However, analyses of root causes and systems drivers - and not just push and pull factors - are also needed. There are common systems' factors at work within destination countries, as reported earlier, such as the channelling of foreign-trained doctors and nurses towards rural populations, poorer urban areas, and less desirable (and less lucrative) specialties. Developing a new lens for viewing the migration of health professionals, which brings together ethics, culture and health systems analyses, can help reframe and stimulate the debate - within as well as across source and destination countries by introducing new ethical perspectives. It is questionable, at the least, if major destination countries, explicitly or by default, channel foreign-trained doctors and nurses into the Primary Care/General Practice posts that especially require culturally appropriately trained staff, as is the case in the United States, ${ }^{13}$ Canada $^{16}$ and Australia. ${ }^{17}$ Whereas hospital specialty posts that require less culturally sophisticated and more specific clinical skills, but are more prestigious and usually better paid, are filled mainly by domestically-trained doctors. Hence, ethical perspectives can inform the analyses of national as well as the global drivers of health workforce migration; and distributive ethics can shed light on how the features of a destination country's health system serve to reinforce local as well as global inequities. However, while this perspective can shift the debate, it cannot be expected to diminish the expedient, passive power of national and possibly professional interests in destination countries, which drive health worker migration. Nor can it be expected to quell the efforts of individual health professionals to migrate and find opportunities to better their lives.

Ethical issues

Not applicable. 


\section{Competing interests}

Authors declare that they have no competing interests.

\section{Authors' contributions}

RB conceptualised and wrote the first draft of the document. SC contributed and edited the document. Both authors reviewed and agreed the final draft.

\section{Endnotes}

[1] The lead author was a member of the Global Policy Advisory Council, which co-drafted the WHO Global Code during a series of seven international meetings in 3 years, 2007-2010.

\section{References}

1. World Health Organization (WHO). WHO Global Code of Practice on the International Recruitment of Health Personnel. http://www.who.int/hrh/migration/code/WHO_global_code_of_ practice_EN.pdf?ua=1. Published 2010.

2. WHO Global Code of Practice on the International Recruitment of Health Personnel. Report of the Expert Advisory Group on the Relevance and Effectiveness of the WHO Global Code of Practice on the International Recruitment of Health Personnel (2010). Geneva: World Health Organization, Sixty-Eighth World Health Assembly: 2015.

3. Taylor AL, Dhillon IS. The WHO Global Code of Practice on the International Recruitment of Health Personnel: The Evolution of Global Health Diplomacy. http://blogs.shu.edu/ghg/files/2011/11/ Taylor-and-Dhillon_The-WHO-Global-Code-of-Practice-on-theInternational-Recruitment-of-Health-Personnel_Fall-2011.pdf. Published 2011.

4. Siyam A, Zurn P, Rø OC, et al. Monitoring the implementation of the WHO Global Code of Practice on the International Recruitment of Health Personnel. Bull World Health Organ. 2013;91:816-823.

5. Edge JS, Hoffman SJ. Empirical impact evaluation of the WHO global code of practice on the international recruitment of health personnel in Australia, Canada, UK and USA. Global Health. 2013;9:60. doi:10.1186/1744-8603-9-60

6. Aluttis C, Bishaw T, Frank MW. The workforce for health in a globalized context-global shortages and international migration. Glob Health Action. 2014;7:23611. doi:10.3402/gha.v7.23611

7. Tankwanchi AB, Ozden Ç, Vermund SH. Physician emigration from sub-Saharan Africa to the United States: analysis of the 2011 AMA physician masterfile. PLoS Med. 2013;10(9):e1001513. doi:10.1371/journal.pmed.1001513

8. Wright D, Flis N, Gupta M. The 'Brain Drain' of physicians: historical antecedents to an ethical debate, c. 1960-79. Philos Ethics Humanit Med. 2008;3:24. doi:10.1186/1747-5341-3-24

9. Zubaran C. Balancing the act: The international migration of medical graduates. Monash Bioeth Rev. 2011;29(3):05.1-12.

10. World Health Organization (WHO). The World Health Report working together for health. http://www.who.int/whr/2006/whr06_ en.pdf. Published 2006.

11. O'Brien P, Gostin L. Health Worker Shortages and Global Justice. Melbourne Legal Studies Research Paper 2011;569. http://ssrn.com/abstract=1965786.

12. Crisp N, Chen L. Global supply of health professionals. N Engl J Med. 2014;370(10):950-957. doi:10.1056/NEJMra1111610

13. Tankwanchi AB, Vermund SH, Perkins DD. Monitoring subSaharan African physician migration and recruitment postadoption of the WHO code of practice: temporal and geographic patterns in the United States. PLoS One. 2015;10(4):e0124734. doi:10.1371/journal.pone.0124734

14. Chen PG, Auerbach DI, Muench U, Curry LA, Bradley EH. Policy Solutions to Address the Foreign-Educated and Foreign-born Health Care Workforce in the United States. Health Affairs. 2013;32:1906-1913.

15. Mick SS, Worobey JL. The future role of foreign medical graduates in U.S. medical practice: projections into the 1990s. Health Serv Res. 1986;21:85-106.

16. Bourgeault IL, Neiterman E, LeBrun J, Viers K, Winkup J. Brain Gain, Drain and Waste: The Experiences of Internationally Educated Health Professionals in Canada. CIHR/Health Canada Chair in Health Human Resource Policy; 2010.

17. Australian Government Department of Health and Ageing. Medical Training Review Panel 11th Report. DoHA; 2008.

18. Supplement (forthcoming). Reviewing the relevance and effectiveness of the WHO Global Code of Practice on the International Recruitment of Health Personnel. Human Resources for Health; 2015.

19. Bradby H. International medical migration: A critical conceptual review of the global movements of doctors and nurses. Health (London). 2014;18(6):580-596. doi:10.1177/1363459314524803

20. Mills EJ, Kanters S, Hagopian A, et al. The financial cost of doctors emigrating from sub-Saharan Africa: human capital analysis. BMJ 2011;343:d7031. doi:10.1136/bmj.d7031 